\title{
OBSERVATIONS ON BACKGROUND RESIDUES IN ANIMAL FATS
}

\author{
D. L. HARRISON \\ Wallaceville Animal Research Centre, Private Bag, Wellington
}

\section{Summary}

Results of recent experimental work, surveys and routine testing indicate that low-level contamination must be expected in animal fats for several years after pastures have been topdressed with stable insecticides. The main source of this persisting background contamination is from insecticides that persist in the topsoil. The significance of this aspect of residues is discussed in relation to current food tolerances and to the future use of insecticides on farm land.

\section{INTRODUCTION}

WHERE stable insecticides are applied topically to established pasture to control soil-inhabiting pests, undesirably high residues of insecticides and their metabolites in meat and milk can be avoided by allowing a suitable interval between the time the pasture is treated and the first grazing by stock. The longer this interval, the lower the residues in animal fat and this applies from the moment of topdressing until most of the insecticide deposited initially on the pasture has been dissipated by mechanical loss, weathering, and dilution by the bulk of new plant growth.

As far as the pasture is concerned, the conditions favouring low residues are the treatment of short, dry pasture with insecticides formulated as granules or prills, followed by a period of rapid growth prior to the introduction of stock - conditions most likely to obtain in spring and autumn.

These principles have formed the basis of insecticide use on New Zealand farmland. Results of routine testing for insecticide residues in animal fats over several years confirm that, for the particular pests and methods of New: Zealand grassland farming, this approach to the problem of residues has been reasonably effective in maintaining residues within tolerances that were acceptable during this period.

Until recently most residue studies were restricted to determining practical withholding periods for the persistent insecticides - little was known of sub-tolerance insecticide contamination in animals subsequent to the first grazing of insecticide-treated pasture or of the significance of insecticides in topsoil which contained virtually all of the insecticides applied. The main limiting factor was the relative insensitivity of the analytical methods available both for research and for continuous checking of primary produce. The recent availability of gas chromatography provides a technique with much greater sensitivity than previous chemical methods and one which is ideally suited for monitoring low residues in foodstuffs. It is appropriate, therefore, that the residue situation should be re-assessed in the light of new information that is now becoming available. 


\section{EXPLANATORY NOTES}

Residues in the fat of animals exposed to DDT usually comprise pp'DDT together with metabolites DDD and DDE, the relative proportions of these components depending on the period and level of exposure. In general, a high level of pp'-DDT and lower levels of DDD and DDE indicate recent high-level exposure to DDT. Where DDE predominates, this indicates either long-term low-level exposure to DDT, a considerable time lapse since a high level of exposure to DDT, or exposure mainly to DDE. For brevity, the term total DDT is often used and this term denotes the arithmetical sum of the individual residues of $\mathrm{pp}^{\prime}$-DDT, DDD and DDE which are present in a sample.

The term background residues (or contamination) used in this paper refers to residues detected in animal tissues long after the normal withholding period and which are derived from various sources in the farm environment.

\section{EXPERIMENTAL DATA}

Lindane AND DDT Residues in WaLlaceville SHeEP AND SoIL

Except for experimental areas, no DDT has been applied at Wallaceville since 1961 when most of the farm area was topdressed at the rate of $2 \mathrm{lb}$ DDT/acre. Sheep drawn from the Wallaceville flock usually have a low background level in body fat of DDE only. For example, 26 ewe hoggets tested in 1965 had a mean DDE level of $0.15 \mathrm{ppm}$ (range 0 to $0.2 \mathrm{ppm}$ ). In 1967, eleven ewe hoggets had a mean DDE level of $0.3 \mathrm{ppm}$ (range 0.2 to $0.5 \mathrm{ppm}$ ). Two areas on which experimental sheep are kept in reserve contain 0.1 and $0.2 \mathrm{ppm}$ DDT in the top inch of soil. The low residues in Wallaceville sheep are therefore consistent with low levels in the soil and with previous history of DDT usage.

On the other hand, one experimental paddock $(24 \mathrm{~A} / 1)$ has received a total of $16 \mathrm{lb}$ DDT/acre and $2 \mathrm{lb}$ lindane/acre since 1961. Previous applications of DDT were in 1961, 1962 and 1963 at the rate of $2 \mathrm{lb}$ DDT/acre. The last treatment with DDT was $10 \mathrm{lb}$ DDT/acre in 1965 and a single treatment with lindane was applied in 1966. Insecticide residues in ewe hoggets grazed recently on this paddock were as follows:

\section{Lindane}

Four sheep were grazed for 36 days from immediately after topdressing on November 15, 1966, and the resulting residues of lindane in their fat ranged from 3.5 to $4.6 \mathrm{ppm}$ (mean, $4.0 \mathrm{ppm}$ ). During the next year, three other groups of eight sheep were grazed on this paddock. The resulting residue figures are given in Table 1 . All sheep were initially free from lindane and the rate of stocking in each grazing period was 32 ewes/acre.

TABLE 1: LINDANE RESIDUES IN SHEEP FAT

\begin{tabular}{|c|c|c|}
\hline \multirow{2}{*}{$\begin{array}{l}\text { Period of grazing } \\
\text { after topdressing } \\
\text { (weeks) }\end{array}$} & \multicolumn{2}{|c|}{$\begin{array}{l}\text { Residues in fat } \\
(p p m)\end{array}$} \\
\hline & Range & Mean \\
\hline $17-21$ & $0.4-1.7$ & 0.9 \\
\hline $33-39$ & $0.3-0.7$ & 0.4 \\
\hline $53-57$ & $0.2-0.4$ & 0.3 \\
\hline
\end{tabular}




\section{$D D T$}

Five sheep were grazed on paddock $24 \mathrm{~A} / 1$ for a period of 19 days, beginning 11 days after the area was topdressed at the rate of $10 \mathrm{lb}$ DDT/acre on March 15, 1965. The resulting residues in their fat ranged from 2.4 to $4.9 \mathrm{ppm}$ total DDT (mean, $3.6 \mathrm{ppm}$ ). Two years and four months later, eight sheep were grazed on the paddock from July 8, 1967, until August 15, 1967 (38 days), and the total DDT content of their fat increased from the pre-trial level of $0.4 \mathrm{ppm}$ (range 0.2 to $0.5 \mathrm{ppm}$ ) to $1.2 \mathrm{ppm}$ (range 0.6 to $1.9 \mathrm{ppm}$ ). Four months later another eight sheep were grazed for four weeks on the next regrowth of pasture and the total DDT in their fat increased from $0.9 \mathrm{ppm}(0.6$ to $1.2 \mathrm{ppm})$ to $1.2 \mathrm{ppm}(0.6$ to $1.9 \mathrm{ppm})$. The rate of stocking in the two latter periods was 32 ewes/acre. During the first period (July/August) the pasture was carrying a considerable amount of soil owing to the wet conditions prevailing but conditions during the second period (November/December) were relatively dry.

\section{Soil Residues}

Topsoil on paddock 24 A/1 was sampled on September 2, 1967, ten months after topdressing with lindane and 28 months after the last topdressing with DDT. Residues, expressed on a dry matter basis, are shown in Table 2.

TABLE 2: RESIDUES IN TOPSOIL (ppm)

\begin{tabular}{ccccc}
\hline Soil depth (in.) & Lindane & $D D E$ & $D D D$ & $D D T$ \\
\hline $0-\frac{1}{2}$ & 3.6 & 1.9 & 3.3 & 21.7 \\
$0-1$ & 2.7 & 2.1 & 3.9 & 20.5 \\
$1-2$ & 0.4 & 1.8 & 3.7 & 20.4 \\
$2-3$ & 0.09 & 1.3 & 1.5 & 9.0 \\
$3-4$ & 0.03 & 0.8 & 0.8 & 5.3 \\
$4-5$ & 0.03 & 0.5 & 0.6 & 3.5 \\
$5-6$ & 0.01 & 0.3 & 0.2 & 1.2 \\
\hline
\end{tabular}

The soil analyses show that there was little penetration of either lindane or DDT into the soil, the lindane being held in the top inch while DDT and related compounds were mostly held in the top two inches.

These experiments confirm that the observance of a suitable withholding period after topdressing will prevent high residues of lindane and DDT occurring in sheep. It is also apparent that low level contamination of fat with insecticide derived from topsoil can be detected for some years after topdressing.

Lindane and DDT Residues in Winchmore SheEp and Soil

During June and July 1967, omental fat was sampled from 73 ewe hoggets of the Winchmore Station flock. All animals contained relatively high residues of total DDT but lindane was not detected. The major residue component was DDE but 71 of the 73 sheep contained at least $0.1 \mathrm{ppm}$ DDT. This indicates that these stock had had long-term exposure to low levels of DDT and that exposure was still continuing. Analysis 
of topsoil from the four experimental areas involved in the 1967 trials showed that an appreciable amount of DDT was still present although DDT was last applied on these areas in 1964, three years previously. No lindane was detectable in the soils. Residues are shown in Table 3, the figures for soil being expressed on a dry matter basis.

TABLE 3: RESIDUES IN SOIL AND SHEEP FAT (ppm)

\begin{tabular}{|c|c|c|c|c|}
\hline \multicolumn{2}{|l|}{ Sample details } & Insecticide & Range & Mean \\
\hline Omental fat (71 sheep) & $\ldots$ & $\begin{array}{l}\text { DDT } \\
\text { DDE } \\
\text { lindane }\end{array}$ & $\begin{array}{r}0-1.8 \\
1.0-3.9 \\
-\end{array}$ & $\begin{array}{r}0.3 \\
1.9 \\
\text { Nil }\end{array}$ \\
\hline Topsoil* & & & & \\
\hline Area 1 (12 paddocks) & $\ldots$. & Total DDT & $7.9-13.8$ & 10.3 \\
\hline Area 2 (4 paddocks) & $\ldots$. & Total DDT & $6.0-8.6$ & 7.2 \\
\hline Run-off area $A$ & $\ldots$ & Total DDT & & 8.6 \\
\hline Run-off area W & $\ldots$ & Total DDT & & 2.1 \\
\hline
\end{tabular}

* Sampling depth 1 in.

In sheep that were not exposed to areas newly topdressed with DDT, a relatively constant background level of total DDT was maintained in their body fat over an eight-month period. In other sheep that were exposed to pastures newly-treated with lindane or DDT, there was a temporary increase in residues of these insecticides in body fat followed by a decrease to pre-trial background levels when the sheep were removed from the newly-treated areas. Furthermore, there were measurable increases in background levels of lindane or DDT in body fat of sheep that were grazed for a second time on DDT or lindane treated areas four and seven months after topdressing. The only logical source of the continuing background residues of both DDT and lindane in these sheep was insecticide shown to be contained in the topsoil (see under Soil Ingestion).

\section{SOIL INGESTION}

Harrison (1966) reported the results of a trial in which soil containing $47 \mathrm{ppm}$ of $\mathrm{pp}^{\prime}$-DDT was administered to sheep by stomach in daily doses of either $\frac{1}{2} \mathrm{lb}$ or $1 \mathrm{lb}$ over a 13-day period. In the fat of the two groups of sheep so treated, the mean levels of pp'-DDT increased from 0.2 to $3.5 \mathrm{ppm}$ and from 0.2 to $5.6 \mathrm{ppm}$, respectively. Both the level of DDT in the soil and the amounts of soil administered in the high-dose group are now considered to be considerably higher than would obtain in practice. Nevertheless, the experiment demonstrated that low-level DDT contamination of fat was possible in practice through sheep ingesting soil containing DDT.

More recently, trials in Canterbury have shown that the amount of soil ingested by sheep varied inversely with pasture length and that soil intakes of the order of $100 \mathrm{~g} / \mathrm{kg}$ dry matter feed consumed were possible under relatively dry weather conditions (Harrison, Rudman and Mol, unpublished data). Healy et al. (1966), in a study of wear in sheep's teeth, calculated that individual ewes on three farms ingested about 1, 10 and $25 \mathrm{lb}$ of soil, respectively over a three-month period. The latter quantity was equivalent to a mean daily soil intake of about $125 \mathrm{~g} / \mathrm{sheep} /$ day.

On this evidence there is little doubt that soil ingestion is a significant cause of insecticide residues in sheep fat. 
Recent analyses of milk from individual dairy farms in the Waikato district (12 farms) and Taranaki district (14 farms) showed that residues, predominantly of DDE, were present in all samples. In general, the residue levels were in proportion to the level of total DDT in the topsoil $(0-1$ in depth) and to the total amount of DDT previously applied on these farms. More comprehensive surveys of farm milk supplies are now being carried out and these include measurements of soil intake by dairy cows on individual farms.

\section{Meat Screening Programme 1966-67}

Lambs, sheep, prime beef stock and culled dairy stock were sampled on a random basis throughout the country during the year and it is most unlikely that more than a small proportion of the farms from which these stock originated would have had recent treatment with DDT relative to the time the stock was sampled. However, although virtually every sample of fat contained at least a trace of DDE, only 50 individual samples from the 23,610 samples tested had a total DDT content above $7 \mathrm{ppm}$. The sub-tolerance DDT residues in the majority of cases probably reflected :he degree to which meat stock were being exposed to DDT in their environment.

It was observed that the proportion of samples containing total DDT residues between 2 and $7 \mathrm{ppm}$ was higher for lambs and sheep than for cattle. This is compatible with the fact that pastures are grazed shorter by sheep than by cattle so that insecticide contamination from soil ingestion would probably be higher for the former.

\section{Mechanism of INSECTICIDE UPTAKe FROM SoIL}

Recent work by Collett and Harrison (1968) indicated that at least two factors were involved in the transfer of lindane from topsoil into grazing sheep. One of these was physical transfer of topsoil containing lindane on to pasture by sheep during grazing and the ingestion of this soil with the pasture. Also, in long pasture that had not been grazed, lindane was apparently contained in the surface waxes of the plants, these residues being significantly higher in the lower parts of the plants than in the upper portions.

Systemic uptake usually refers specifically to the absorption of insecticide from soil by plant roots and translocation to the aerial parts of the plant. Although there has been little critical study of this type of residue in pastures in New Zealand, there is presumptive evidence that it may occur with heptachlor (Solly, et al, 1968) and with fensulfothion (Solly, 1968). Collett and Harrison (1968) found little evidence of systemic uptake of lindane by pasture from soil which contained approximately $1 \mathrm{lb}$ lindane/acre when the pasture was sampled. There is no evidence that DDT is systemic in pasture in amounts that would be significant in relation to the levels that are being found in animal fats.

\section{TRANSFER OF INSECTICIDES FROM EWE to LAMB}

This aspect of lindane and DDT residues has been examined by Harrison and Mol (1968). Of particular interest was the apparent uptake of DDT from soil by both the group of control ewes and the two groups of lindane-treated ewes during the six-month trial and the ensuing transfer of this DDT to lambs via the milk. This type of secondary contamination would be expected in both lambs and calves with any insecticide that is 
stable in soils and preferentially soluble in fats. Other evidence of the transfer of insecticides from ewes to lambs has been reported for heptachlor epoxide (Solly et al., 1968) and for dieldrin (Harrison, 1962).

\section{Miscellaneous Sources of Background Contamination in Stock}

Stable insecticides can persist in both hay and silage and these supplementary feeds could be a constant source of insecticide intake for the periods during which they are fed to stock. The utilization as stock feed of cannery wastes and rejected fruit from orchards may also cause residue problems although this practice is confined to a limited number of farms in fruit-growing districts.

No surveys have been carried out on insecticide residues in farm water supplies. However, analyses of water taken from rivers and lakes that drain land that has been topdressed with DDT and dieldrin indicate that residues in most water supplies would be a few parts per thousand million. Residues of this order would be of negligible significance in the overall problem of animal fat contamination.

\section{DISCUSSION}

Except for specified uses of lindane (Anon., 1961) organochlorine insecticides have been prohibited as ingredients of animal remedies in New Zealand for seven years. Residues of organochlorine chemicals that now appear in animal fats are therefore derived solely from the ingestion of agricultural chemicals either on, in, or in association with feedstuffs. DDT is still the predominant chemical in this group with lindane as an alternative where there is proven resistance to DDT in grass grub populations. Aldrin and dieldrin were previously used against specific pests on grazing pastures but their use is now restricted to horticultural pests as is the case with DDD and some organochlorine acaricides. Heptachlor was used experimentally on a few farms but its use is now confined to areas that will not be grazed by stock.

From the national viewpoint, stock are exposed to DDT more than to any other insecticide. Possibly adverse economic effects are offset, to some extent, by the tolerances for DDT at present permitted in meat fat and milk fat. Whether or not there is justification for any reduction of these tolerances, it is clear that any such change would inevitably narrow the gap between residues that will be acceptable and residues that are unavoidable as a result of present (and past) use of DDT. These aspects should be critically examined in the light of information that is now becoming available.

The experimental data presented confirm that low-level contamination of animal fats must be expected for some years after pastures have been topdressed with DDT or lindane. Residues in fat represent an equilibrium between intake and excretion (Barnes, 1967) so that the continuing presence of background residues in animal fats means that stock are being exposed continuously to low-level intakes of insecticides. Where growing pasture is the major or sole item of diet, the only source of these residues is insecticide that has been shown to lodge in the top inch or so of topsoil. There is accumulating evidence that stock on free range ingest considerable quantities of soil with their feed. Supplementary feedstuffs, if they contain residual insecticides, will also contribute to the total of background residues in stock. This would occur, however, only during feeding-out periods, contamination during the remainder of the year being derived from the soil. 
These observations will be true for any insecticide that is stable in soil and preferentially soluble in fats. In all cases, the degree of contamination from soil will depend on the particular insecticide, the rate and frequency of application, systemic properties if any, together with such factors as rainfall, grazing pressure and possibly soil type. Where an insecticide has been ascribed a "nil" tolerance in animal fat, it is apparent that it is virtually impossible to use it for the treatment of established pasture without traces appearing in animal fat - traces which can now be detected readily by gas chromatography. Incorporation of such chemicals in soil at the time of sowing new pasture may be acceptable (except for chemicals that are systemic) but this practice could only be recommended after field trials have been carried out.

There is no evidence that soil residues of DDT are more "available" to stock than plant residues. Some assessment of the significance of DDT residues in soil in relation to residues in stock can therefore be made on the basis of present knowledge. For sheep, $5 \mathrm{ppm}$ DDT on pasture (dry matter basis) is considered an acceptable dietary limit in respect of the New Zealand tolerance of $5 \mathrm{ppm}$ for DDT in meat fat (Harrison, 1966). Assuming that the maximum amount of soil ingested daily by a sheep is $200 \mathrm{~g}$ in a total dry matter intake of $1 \mathrm{~kg}$ (W. B. Healy, pers. comm.), it can be calculated that $25 \mathrm{ppm}$ DDT in topsoil should be an acceptable level for this species. For lactating cows, $0.5 \mathrm{ppm}$ DDT on pasture (dry matter basis) is considered an acceptable dietary limit in respect of the level of $1.25 \mathrm{ppm}$ of total DDT at present permitted in milk fat (Laben et al., 1966; unpublished data, Research Division, Department of Agriculture). Assuming that the maximum amount of soil ingested daily by a cow is $1 \mathrm{~kg}$ in a total dry matter intake of $10 \mathrm{~kg}$ (W. B. Healy, pers. comm.) it can be calculated that $5 \mathrm{ppm}$ DDT in topsoil should be an acceptable level for lactating cows. In other words, it would be most unlikely that the present tolerances for DDT in meat fat and for milk fat would be exceeded where DDT levels in topsoil are less than 25 ppm (for sheep) and less than $5 \mathrm{ppm}$ (for cows).

From data that are available, the average residue of DDT in the topsoil $(0-1 \mathrm{in}$. depth) of an individual farm would rarely approach $25 \mathrm{ppm}$, which is approximately equivalent to $8 \mathrm{lb}$ DDT/acre. Further controlled usage of DDT on sheep farms is therefore justified. The results being obtained from the national meat screening programme support this conclusion. For dairy farms, however, the limit for DDT in topsoil $(0-1$ in. depth) of $5 \mathrm{ppm}$ is approximately equivalent to $2 \mathrm{lb}$ DDT/acre. Therefore, where all the grazing areas on a dairy farm have received a total of $2 \mathrm{lb}$ DDT/acre, further applications of this insecticide could not be recommended, possibly for several years. Here again, the results of surveys of DDT residues in milk fat and in the topsoil from individual dairy farms support this conclusion.

Problems of residues in animal fats are by no means unique to New Zealand. What is unique is the difficulty of controlling a soil-inhabiting pest like the grass grub under a system of animal husbandry that is based predominantly on the grazing of permanent pastures. For dairying in particular, the use of persistent insecticides has always been overshadowed by the spectre of the "nil" tolerance, the administrative value of which has decreased progressively in step with the increasing sensitivity of analytical methods. It is fortunate, on the one hand, that the major residue problems are virtually limited to DDT and its metabolites. On the other hand, it is apparent that the build-up of DDT in topsoil coupled 
with an increasing resistance to DDT in grass grub populations must eventually limit its use and effectiveness.

\section{REFERENCES}

Anon., 1961: N.Z. Gazette, 58: 1,401.

Barnes, J. M., 1967: Span, 10: 7-8.

Collett, J. N.; Harrison, D. L., 1968: N.Z. J. Agric. Res. (in press).

Harrison, D. L., 1962: Proc. 6th Tech. Conf. N.Z. Fert. Manuf. Res. Assn.: $18-23$.

, 1966: Proc. 19th N.Z. Weed \& Pest Control Conf.: 261-6.

Harrison, D. L.; Mol, J. C. M., 1968: Proc. 21st N.Z. Weed \& Pest Cont. Conf.: 233-9.

Healy, W. B.; Ludwig, T. G.; Cutriss, T. W., 1966: J. N.Z. Inst. Agric. Sci., 1: 23-7.

Laben, R. C.; Archer, T. E.; Crosby, D. G.; Peoples, S. A., 1966: J. Dairy Sci., 49: 1988-94.

Solly, S. R. B., 1968: Proc. 21st N.Z. Weed \& Pest Control Conf.: $250-5$.

Solly, S. R. B.; Harrison, D. L.; Shanks, V., 1968: N.Z. J. Agric. Res. (in press). 